\title{
Effects of temperature on COVID-19 transmission in India
}

\author{
Indranil Bhattacharjee ${ }^{1}$, Anuradha Deb ${ }^{1}$, Priyanka Sarangi ${ }^{1}$, Biplab Mandal ${ }^{2}$, and Partha \\ Chakravorty $^{1}$ \\ ${ }^{1}$ Raja Narendra Lal Khan Women's College \\ ${ }^{2}$ Vidyasagar University
}

June 4, 2020

\begin{abstract}
This study analyzed the corelation between COVID-19 and temperature in India. Secondary published data from different websites is used by us. The climate indicators included in the study are maximum temperature, minimum temperature. Kendall and Spearman rank correlation tests were chosen for data analysis. We find that maximum temperature has significant relations associated with the COVID-19 pandemic. The findings of this study will help health regulators to combat COVID-19 in India and the rest of the world.
\end{abstract}

\section{Introduction}

Novel Corona Virus (COVID-19), is associated with the respiratory disorder in humans which has been declared as a global epidemic and pandemic in the first quarter of the year 2020 by the World Health Organization (https://www.who.int/ novel-coronavirus-2019). People with lowimmunity, old age, immunocompromised and medical problems specially related to lungs, diabetes, cardiac related problems are more prone to Covid 19 disease. The symptoms are cough, cold, breathing problem very similar to flu. Exact transmission route of COVID-19 is yet to be identified; it was transmitted mainly by respiratory droplets in humans (Ge et al., 2013; Huang et al., 2020). Climate conditions are classified as top predictors of coronavirus illnesses (Dalziel et al., 2018). Climate factors includes wind speed, humidity, temperature (Yuan et al., 2006; Bashir et al. 2020). Bull (1980) reported that pneumonia's mortality rate is highly correlated with weather changes. Preventive measures are to protect oneself by washing hands frequently, avoiding touching the mouth, nose, and face, and by maintaining social distancing ( 1 meter or 3 feet) with other people. It is reported that there are two important stages of Covid 19; stage-II and stage-III. In stage-II, there is person-to-person transmission and in stage-III, there is a community transmission. The first case of Covid 19 was reported in India on 30 January 2020, originating from China. All most after two months this disease spread in almost all parts of India. Majority of countries of world have noticed a huge number of Covid 19 cases from December 2019 onwards. India is being looked upon by various nations now as a World Leader and even WHO acknowledged that world is looking towards Indian strategies to contain the outbreak of this epidemic (Sharma, 2020). India accounts for almost one-fifth of the world's population and is second leading country in terms of population in the world. India contributes heavily to the world's GDP and is amongst the most prominent developing country in the world with fairly strong economic growth percentages (Myers, 2020). India's good closeness with majority of the nations in the world and its helpful nature makes it a perfectally for other countries. Therefore, the analysis of COVID-19 outbreak in Indian region is closely watched and monitored by the World and there is a need of comprehensive analytical studies based on different strategies taken by Indian administrators.

In this study, we aimed to ascertain the relation between maximum and minimum temperatures with COVID 19 disease rates over India. 


\section{Research methodology}

India is the seventh-largest country in the world, situated north of the equator between $8^{\circ} 4$ ' north to $37^{\circ} 6$ ' north latitude and $68^{\circ} 7^{\prime}$ to $97^{\circ} 25^{\prime}$ east longitude (India year Book, 2007) with a total area of 3,287,263 square kilometres (1,269,219 sq mi) (India, 2012). In India there are 28 states and 8 Union Territories (States and Union Territories, 2020). India is the worlds second most populous country (1.2 billion, census, 2011) after Peoples Republic of China. India has 614000 inhabited villages and 72.2 percent of the total population reside in this rural areas (Census, 2011, Provisional Population Totals) . On the basis of net migrants by last record Maharasthra had most immigartion with 2.3 million, followed by Delhi (1.7 million), Gujarat (0.68 million), Haryana (0.67 million). Uttarpardesh and Bihar topped the list for interstate emigration. The States of Uttar Pradesh, Maharasthra, Bihar, West Bengal and Madhya Pradesh accounts for almost half (48.89 percent) of the Total Indian Population (India Census, 2011). According to report of National Institution for Transforming India, Government of India the population density of State of West Bengal (1029 persons per sq $\mathrm{km}$ ) is highest followed by Bihar (1102 persons per sq $\mathrm{km}$ ) and among Union Territories the population density of Delhi (11297 persons per sq km) is highest followed by Chandigarh (9252 persons per sq km). Secondary published data from different websites is used by us. Dataset for the climate indicators includes high temperature and low temperature. As the data was not normally distributed therefore Kendall and Spearman rank correlation statistical tests were utilized to examine the correlation between variables using , SPSS 20 and XLSTAT software (Addinsoft, 2010).

\subsection{Data availability statement}

Dataset for COVID-19 is taken from January30, 2020-May 10, 2020, from the https://en.wikipedia.org/wiki/Template:COVID19_pandemic_data/India_medical_cases_summary\#cite_note-2 and the data for climate indicators was taken from https://weather.com/en IN/weather/monthly.

\section{Results and discussion}

Sharp rise in daily infective as well as active cases are noted together with mortality rate. But in a dense country like India recovery rate is also satisfactory. India is considered as warm country and temperature plays important role in spread of COVID-19. During the Year 2020, maximum temperature varies from 2 to $45^{\circ} \mathrm{C}$ and minimum temperature varies from -5 to $31^{\circ} \mathrm{C}$. With rise of temperature the droplets which falls on the ground immediately dries due to extreme temperature. The areas where the daily fluctuation rate of temperature is high suffers a lot. In India from March onwards the COVID-19 is at its peak the temperature is also not so much high but from April onwards there is slight decline in number of cases (Figure 1). But spread of any pandemic diseases also depends upon personal contact. Government of India implemented strict rules of Lockdown as there is no other alternatives as there is no vaccine and no other medicines to control them. Less number of cases in dense country like India is also possible due to strong implementation of lockdown.

The temperature dependency of COVID-19 may be similar to that of SARS-Cov which loses its ability to survive in higher temperatures (Chan et al., 2011), due to the breakdown of their lipid layer at higher temperatures (Schoeman and Fielding, 2019). With approaching summer, there is redundancy in number of cases it may also be that the temperature ranges we have seen so far for most of the cases upto 17 to 18 ${ }^{\circ} \mathrm{C}$ the virus is at its peak but as the temperature approaches tpwards $25^{\circ} \mathrm{C}$ the peak gradually declines.

Table 1 and Table 2 presents the empirical correlation coefficients with scatter plot on Figure 2 . From both tables it is clear that tempmax has more positve correlation with distribution of COVID-19. It clearly suggests that maxtemperature has inhibitory effect on COVID-19 whereas minmtemp supports the spread of the disease. Previous studies of Tan et al. (2005) and Vandini et al. (2013) support our findings. Shi et al. (2020) and Bashir et al. (2020) also researched climate indicators and stated that temperature serves as a driver for the COVID-19.

Despite strong evidence of temperature association with COVID-19, provides the following limitations. First, more variables are needed to conduct a comprehensive study as COVID-19 is an infectious disease and it is 
affected by many variables such as humidity, rainfall, wind speed, social distancing, people's endurance and availability of health facilities. Second, data about personal hygiene indicators such as hand wash needs to be explored in further studies.

\section{Conclusion}

Climate plays important role in the fight against COVID-19 in country like India. This study finds that maximum temperature significant correlated with COVID-19 pandemic and will be useful in suppressing COVID-19. Current study is of exploratory nature and in order to conduct a comprehensive investigation, future research direction should examine daily carbon emission data as current lockdown measures have greatly reduced carbon emissions. Another research direction is to include regional and cross-country investigations for most affected countries to provide better insight for the fight against COVID-19.

\section{Conflict of Interest Statement}

We declare that we have no conflict of interest

\section{Funding information}

No funding from any source

\section{Credit Authorship contribution statement}

IB- Data curation, Writng Original Draft, Statistical analysis,AD- Data Curation, PS - Data Curation, BM - Reviewing, Editing, PPC - Designing, Monitoring, Reviewing, Communication

\section{Acknowledgment}

Authors are grateful to PG Department of Zoology, Raja Narendra Lal Khan Women's College (Autonomous), Paschim Medinipore, West Bengal, India for the facilities provided.

\section{Ethical Statement}

No ethical approval was required because we used the secondary published data from different websites.

\section{References:}

Addinsoft, SARL( 2010). XLSTAT software. Version 10.0. Paris, France.

Bashir, M. F., Ma, B., Bilal., Komal, B., Bashir, M.A., Tan, D., Bashir, M., 2020. Correlation between climate indicators and COVID-19 pandemic in New York, USA. Sci. Total Environ 728, 138835.

Bull, G., 1980. The weather and deaths from pneumonia. Lancet 315, 1405-1408

Census., 2011. Provisional Population Totals. The Hindu. Chennai India. Archieved from the original on Nov $3,2013$.

Chan, K. H., Peiris, J.S.M, Lam, S.Y., Poon, L.L.M., Yuen, K.Y., Seto, W.H., 2011. The Effects of Temperature and Relative Humidity on the Viability of the SARS Coronavirus. Advances in Virology vol. $1-7$.

Dalziel, B.D., Kissler, S., Gog, J.R., Viboud, C., Bjornstad, O.N., Metcalf, C.J.E., 2018. Urbanization and humidity shape the intensity of influenza epidemics in U.S. cities. Science 362, 75-79

Ge, Y., Li, J., Yang, X., Chmura, A., Zhu, G., Epstein, J., Mazet, J., Hu, B., Zhang, W., Peng, C., 2013. Isolation and characterization of a bat SARS-like coronavirus that uses the ACE2 receptor. Nature 503 (7477), 535-538 2013

https://www.who.int/emergencies/diseases/novel-coronavirus-2019 [Accessed on May 25, 2020].

Huang, C., Wang, Y., Li, X., Ren, L., Zhao, J., Hu, Y., Zhang, L., Fan, G., Xu, J., Gu, X., 2020. Clinical features of patients infected with 2019 novel coronavirus in Wuhan, China. Lancet 395 (10223), 497-506 
India Census., 2011. The Hindu, Chennai, India. http:// www.thehindu.com/multimedia/archieve/00517/IndiaCensus 2011.

India Year Book., 2007. Publications Division, Ministry of Information \& Broadcasting, Govt. of India. 2007. ISBN 81-230-1423-6.

India, 2012. Encyclopedia Britannica. Retrieved 17 July 2012. Total area excludes disputed territories not under Indian control.

Myers, J., 2020. India is now the world's 5th largest economy, World Economic Forum. Accessed from https://www.weforum.org/agenda/2020/02/india-gdp-economy-growthuk-france/ on 15th March 2020.

Schoeman, D., Fielding, B. C., 2019. Coronavirus envelope protein: current knowledge. Virol. J. 16 , 69.

Sharma, N., 2020. India's swiftness in dealing with Covid-19 will decide the world's future, says WHO, Quartz India. Accessed from https://qz.com/india/1824041/who-saysindias-action-on-coronavirus-criticalfor the-world/ on 25th March 2020.

Shi, P., Dong, Y., Yan, H., Li, X., Zhao, C., Liu, W., 2020. The Impact of Temperature and Absolute Humidity on the Coronavirus Disease 2019 (COVID-19) Outbreak Evidence from China. medRxiv.

States and Union Territories., 2020. Know India Programme. Retrieved 21 April, 2020.

Tan, J., Mu, L., Huang, J., Yu, S., Chen, B., Yin, J., 2005. An initial investigation of the association between the SARS outbreak and weather: with the view of the environmental temperature and its variation. J. Epidemiol. Community Health 59, 186-192.

Vandini, S., Corvaglia, L., Alessandroni, R., Aquilano, G., Marsico, C., Spinelli, M., 2013. Respiratory syncytial virus infection in infants and correlation with meteorological factors and air pollutants. Ital. J. Pediatr. 39 (1).

Yuan, J., Yun, H., Lan, W., Wang, W., Sullivan, S.G., Jia, S., Bittles, A.H., 2006. A climatologic investigation of the SARS-CoV outbreak in Beijing, China. Am. J. Infect. Control 34 (4), 234-236

\section{Hosted file}

Tables .docx available at https://authorea.com/users/329826/articles/456720-effects-oftemperature-on-covid-19-transmission-in-india

\section{Hosted file}

Figures.docx available at https://authorea.com/users/329826/articles/456720-effects-oftemperature-on-covid-19-transmission-in-india 